\title{
Nickel Peroxidase Method
}

National Cancer Institute

\section{Source}

National Cancer Institute. Nickel Peroxidase Method. NCI Thesaurus. Code C113774.

An immunohistochemistry staining method using horseradish peroxidase, DAB substrate, and nickel chloride. 